\title{
ADRESSING UNCERTAINTY AND COMPATIBLITY IN AHP MODELING: PROJECT PORTAFOLIO SELECTTION FOR GEF MEXICO
}

\begin{abstract}
Here we addressed through a practical case the problem of dealing with both the uncertainty in pairwise comparisons and the compatibility amongst alternative AHP representations. Our approach was implemented for integrating a portfolio of projects to be presented by Mexico to the Global Environmental Facility (GEF). Results showed the importance of considering uncertainty/compatibility in AHP implementation aiming to integrate multiple viewpoints from representatives of international institutions, civil society organizations, and the public sector alike.
\end{abstract}

Keywords: uncertainty, compatibility, interval judgement.

\section{Introduction}

The Global Environment Facility (GEF) was established after the 1992 Rio Earth Summit to address global environmental issues while supporting national sustainable development. Nowadays, it finances projects of international institutions, civil society organizations, and the private sector in 183 countries. Projects has to meet the funding priorities, eligibility, and criteria of GEF in order to be integrated in a country's portfolio. Here, we present the AHP model developed to improve the accountability of process for integrating the portfolio of projects in Mexico.

\section{Literature Review}

Integrating a portfolio of projects is multi-criteria decision-making problem encountered by private and public organizations alike (Triantaphyllou 2002). While the AHP has proved capable of dealing with complex contexts, it is necessary in participatory settings to deal with the uncertainty experienced by decision makers in making comparisons pairwise comparison (Saaty and Vargas 1987), and well as with the compatibility amongst possible alternative evaluations (Garuti 2014).

\section{Objectives}

The selection of a GEF portfolio for Mexico entailed an intricate participatory process to combine global environmental issues and concerns and national priorities. The key 
ISAHP Article: A Style Guide for Paper Proposals To Be Submitted to the International Symposium on the Analytic Hierarchy Process 2016, London, U.K.

challenge face by the Mexican government was how to select the best portfolio of projects in a way that overall objectives (both national and global) were maintained.

\section{Method}

The AHP was developed following a group decision making scheme. Approximately 60 partakers of different backgrounds were distributed in four working tables to maximize the diversity of inputs into the model. The goal, criteria, and alternatives were established beforehand according with the GEF procedures, and partakers provided with the respective pairwise judgments.

\section{Model Analysis}

Results synthesized 27 criteria from a four-level hierarchical structure; all comparisons attained consistency (C.I. $<0.1)$

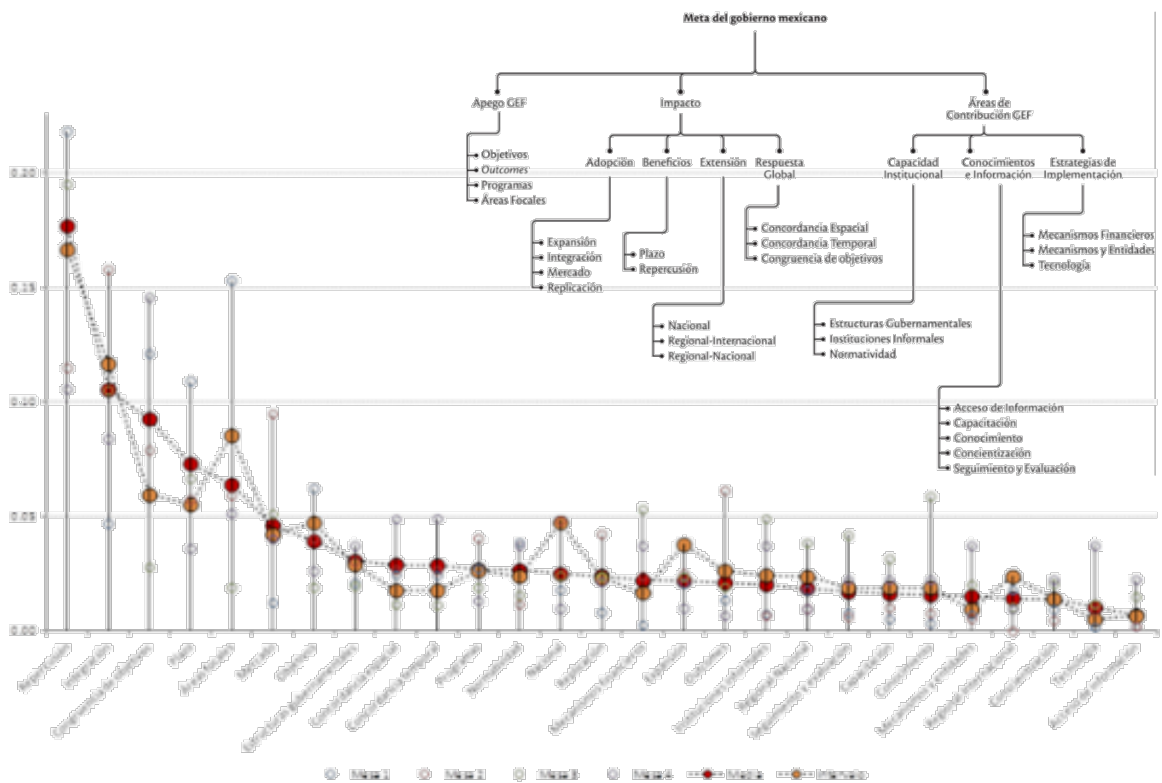

\section{Limitations}

The usefulness of our approach was limited by the lack of experience of many partakers with the AHP, as well as a generalized lack of deep understanding of GEF's goals. A major lesson learned relates to the need for implementing a training in this two aspects.

\section{Conclusions}

We have shown the importance of considering the uncertainty in pairwise comparisons and the consistency among alternative in complex group decision making settings. This not only supports and qualifies the decisions, but also enables the decision makers to justify a particular project portfolio. 
ISAHP Article: A Style Guide for Paper Proposals To Be Submitted to the International Symposium on the Analytic Hierarchy Process 2016, London, U.K.

\section{Key References}

Garuti, C. 2014. Measuring in weighted environments. Kindle Edition. http://www.amazon.com/

Saaty, Thomas L, and Luis G Vargas. 1987. "Uncertainty and Rank Order in the Analytic Hierarchy Process" 32: 107-17.

Triantaphyllou, E. (2002). Multi-criteria decision making methods: A comparative Study, N.Y.: Springer. 